\title{
REVIEWS.
}

\section{AGGRESSIVE MEDICINE.}

By John Maberly, M.R.C.S., L.R.C.P. Baillière, Tindall \& Cox. London, 1935. Price 10/6.

In the short preface to this book the author explains that the original title "Internal Antiseptics" was thought not to be sufficiently descriptive. The present title "Aggressive Medicine" was accordingly substituted, and we are much inclined to agree that it is more appropriate to the work in question!

The sound practice of medicine involves a combination of art and science, and we are the last to deny the usefulness of certain forms of purely empirical treatment or to depreciate the value of many opinions based upon real clinical insight and experience, albeit unsupported by experimental evidence. This volume, however, bears little of the imprint either of science or of art; indeed it is difficult, even with the kindest intentions, to see in it anything more than a cheap and rather unconvincing testimonial to certain proprietary medicines.

- In regard to the possible value of guaiacol preparations, in combination with the halogens, in the treatment of various infective conditions, we are content to keep an open mind, and we would certainly disclaim any attitude of undue scepticism. If, however, the author is anxious to convince the Profession of the almost universal applicability of the three preparations which constitute the main thesis of his book, he will have to bring forward a great deal more evidence than is therein contained.

In common with many similar apotheoses, his remarks are characterized by a sad lack of any real basis, either clinical or pathological, for many of his diagnoses. We hesitate to weary our readers with the details of innumerable examples; the two outstanding instances are meningitis and malignant endocarditis, the miraculous cures of which have left us sorrowfully unconvinced.
The general style of the writing, though it suggests a sincerity of purpose, which we do not for a moment doubt, is clumsy and ill-expressed; the following pathetically humorous example may be quoted (vid. p. of 64., Case 1). "The child had been ill about a fortnight, diagnosed and treated as pneumonia by means of a cough mixture containing among other drugs ammonium carbonate, in a practice of which I was temporarily in charge."

We regret to criticize so hardly a work $\vec{n}$ which we are willing to regard as an honest attempt on the author's part to share an experience which he believes to be of use to suffering humanity, but as a serious contribution to modern Medicine we can- 0 not recommend it to the general practitioner, and least of all to the student.

\section{ANTENATAL AND POST-NATAL CARE.}

By Francis J. Browne, M.D.(Aberd.), D.Sc., F.R.C.S.(Edin.), F.C.O.G., Professor of Obstetrics and Gynæcology, University of London; Director of the Obstetric Unit and Obstetric Surgeon, University College Hospital, London.

London: J. \& A. Churchill, Ltd., 1935. Pp. 480. Price 15/-.

Professor Browne has written this book on "Antenatal and Post-Natal Care," and by doing so he has supplied the Medical Profession with something, for which they have been searching for many months. This book is excellent both in the assembly of its subject matter and in its production. The preservation of the normal in pregnancy receives slightly more attention than is usual in works upon this subject, but further emphasis in this direction might have been given in the chapters on Diet, Induction of Labour and the Conduct of Antenatal Clinics.

An excellent chapter, the first, deals with the history of Antenatal Care, and Professor Browne is able to show that this 
has been practised for some four hundred years. Next in interest, we would place Chapter Six, written by Grantley Dick Read, which deals with the influence of the emotions on Pregnancy and Parturition. This chapter might well be greatly enlarged, and more detailed instructions given in the management of the many fears and delusions, to which a woman may be subject in her first pregnancy.

Considerable time and space are devoted to the problem of "minor degree of disproportion" between the fotal head and the birth canal. In this respect, the author has not spared himself or his readers, and declares with emphasis that examinations of such patients usually are not performed with sufficient care, and that an enormous number of unnecessary premature terminations of pregnancy results. The descriptions he gives of the investigation of such cases are clear and will be of the greatest help. The chapters that deal with Antepartum Hæmorrhage, Toxæmia and with the diseases that may commonly complicate a pregnancy, are good and orthodox. PostNatal Care is described in a chapter of only nine pages, and there may be some who will disagree with Professor Browne, when he advocates the early treatment of cervicitis following childbirth.

The huge Bibliography at the end is an index of the great amount of care that the author has taken in the production of this book on a subject, whose importance has increased so much of recent years, and to which insufficient attention has been given as a rule in the standard text books on Obstetrics.

\section{LOCALIZED RAREFYING CONDITIONS OF BONE.}

By E. S. J. KING, M.D., D.Sc., M.S. (Melb.), F.R.C.S. Edward Arnold \& Co., London. 1935. IPrice 35/-.

For many years now the curious disease of bones which attacks certain selected sites, such as the head of the femur, the scaphoid, the semi-lunar bones of the wrist and the spine, has proved a great puzzle. This book is an attempt to elucidate these conditions and to bring them into line with each other.
As the author points out, the various rarefying conditions met with in bones are really X-ray findings, and the correlation of such evidence with pathological processes has proved to be an almost insuperable difficulty. This is evidenced by the diverse and extensive nomenclature of the disease in whatever bone or bones it attacks. These facts are clearly brought out by the author, who has evidently made a very deep study of the literature, and has had some considerable experience of the condition in his own practice.

The first part of the work is concerned with the structure of bone, and a very clear and comprehensive account is given of its anatomy, physiology and embryology. Osteochondritis is dealt with as a whole, and it is only after going extensively into its various details that the sites attacked are discussed. The author admits the difficulties of pathological explanation, and does not attempt to put forward any view of his own, but it is obvious from his writings that he leans to Leriche's view that the condition is chiefly a vascular one.

Perhaps one of the most striking features of the book is the extensive bibliography, which appears at the end of each chapter. For instance, there are no less than 426 references to osteochondritis of the upper end of the femur. Unfortunately, some of the references are slightly inaccurate in their wording. This is especially true of German references, where in many instances capital letters have been omitted; and sometimes French wording is obviously inaccurate. These are, however, small blemishes which will doubtless be remedied in another edition. The only other criticism that can be made is that some of the skiagrams might be better, and a more comprehensive explanation of them would be an improvement.

The author is much to be congratulated on the amount of work he has done. This book should be of considerable use to those whose lot it is to have to deal with these diseases, which, despite their uncertain path. ology, have to be regarded as definite clinical entities. 